EISSN: $2706-7947$ ISSN: 2077- 4613

DOI: 10.36632/mejas/2021.11.3.55

Journal homepage: www.curresweb.com

Pages: 682-693

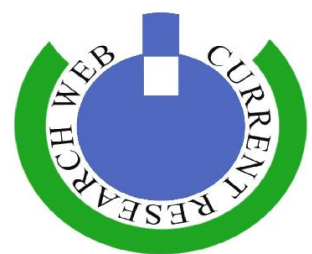

\title{
Egyptian Honey Bee Products as Alternative Agents for Antibacterial Activity and Milk Preservation
}

\author{
Eman M. Abdalla, Mohamed N. Elbassiony and Hatem M. Mahfouz
}

Department of Plant Production, Faculty of Environmental Agricultural Sciences, Arish University, North Sinai 45511, Egypt.

Received: 10 July 2021 Accepted: 30 August 2021 Published: 10 Sept. 2021

\begin{abstract}
The honey bee products have curative properties for many human infections and diseases. The antibacterial activity of honey bee products (bee venom, bee honey, propolis, pollen and royal jelly) at different concentrations against some pathogenic bacteria by zone of inhibition assay (compared to artificial antibiotics) and minimal inhibitory concentration (MIC) to prolong shelf life of dairy product was studied. Also, a growth equation model was used in predicting bacteria growth in milk as a function of time. The results reveal that all bee products exhibited antimicrobial spectrum to some extend among the tested pathogenic bacteria. The highest inhibition zone area (IZA) of growing Escherichia coli, Salmonella typhimurium and Salmonella enterica was recorded with propolis at 20, 40 and $80 \%$, respectively. For Augmentin antibiotic, the highest IZA was found against E. coli $\left(52.8 \pm 7.91 \mathrm{~mm}^{2}\right)$ while both Salmonella sp showed lower IZA. From MIC data, the honey and propolis have a superior effect in inhibiting pathogenic bacteria. The addition of both honey and propolis at a final concentration of $50 \mathrm{mg} / \mathrm{ml}$ had a considerable inhibitory effect on the growth of bacteria compared to control. Inhibitory effect on the growth of bacteria in treated milk with propolis was higher than that of milk treated by honey. In a pragmatic point of view, the model demonstrates that the milk without treatment (control) showed a good growing curve by which the highest growth rate was established at 41.5 days. However, the values in milk treated by honey and propolis were 1.20 and 0.80 days, respectively. The propolis could be used as a natural component to prolong the shelf life of milk.
\end{abstract}

Keywords: Bee products, pathogenic bacteria, milk, preservation

\section{Introduction}

The remedial properties of bee products for many human infections and diseases have been known since ancient decades, particularly as a topical agent to be used on human wounds (Sipos et al., 2004, Rahman et al., 2017). Honey is not the only product of bee workers but also propolis which is a gummy material made from park trees that has anti-bacterial properties. Honey bees also produce royal jelly and pollen for human consumption as a supplementary food. Moreover, honey bee venom is extracted to produce anti-venom therapy and is being investigated as a treatment for several serious diseases of the muscles, connective tissue, and immune system, including multiple sclerosis and arthritis. Honey, bee venom, propolis, pollen and royal jelly are extracted from bee hive keeping, and this operation is widely known and practiced in many African and Asian countries.

On the other hand, resistance of pathogenic bacteria that can infect human to antibiotics can be natural or acquired. The increasing resistance of bacteria to antimicrobial agents has become a worldwide problem. Natural resistance means that the bacterium has either inherited this resistant or it possesses a naturally occurring structure or system that makes bacteria unaffected by the killing factor. Acquired resistance results from a mutation or from the acquisition of a new plasmid or transposon formed by conjugation or transduction or transformation. Escherichia coli for example, has developed resistance to streptomycin by mutation. The using of chemical antibiotic may cause different negative

Corresponding Author: Hatem Mohamed Mahfouz, Department of Plant Production, Faculty of Environmental Agricultural Sciences, Arish University, North Sinai 45511, Egypt

Email: hatemmahfouz@yahoo.com 
effects to people; (i) simple to sever side effects requiring physicians to take extra care when prescribing, (ii) Contribution to cancer accruing, (iii) killing of the normal beneficial flora, (iv) The development of immune suppression and (v) causing environmental pollution problem due to their waste disposal (Ribeiro et al., 2020)

There is therefore a critical need to find new natural compounds to overcome these negative effects, notably in relation to antibacterial resistance. In time, antibiotics will be no longer effective on killing pathogenic microorganisms due to significant increases in resistance and to shortages of synthesising new antibiotics. Replacement with alternative natural and effective products such as honey bee products is therefore gaining a favour in this concern. These products are as diverse from culture to culture and region to region and have been used since antiquity to affect cures. However, the significant shift to antibiotics in the 1940s resulted in the neglect of these treatments, examples of which include apitherapy (i.e. honey therapy). The current work aimed to study the impact of honey bee products (bee honey, bee venom, propolis, pollen grains and royal jelly) as antibacterial agents compared with artificial antibiotics. Also, determine the effect of honey bee products on the shelf live and bacterial inhibitory effect in the milk.

\section{Materials and Methods}

\subsection{Bee products collection and preparation}

Bee products including honey, royal jelly, propolis, bee venom and pollens were obtained from Honey Bee Research Centre (HBRC), Faculty of Environmental Agricultural Sciences, Arish University. All samples were stored in cool condition except honey which stored in dark at room temperature for further use.Propolis raw material was extracted using $70 \%$ ethanol. Briefly, $30 \mathrm{~g}$ propolis was added into $150 \mathrm{ml} 70 \%$ ethanol, shaking in end over end shaker overnight then heated for $60 \mathrm{~min}$ at $50{ }^{\circ} \mathrm{C}$. The supernatant was centrifuged at $3000 \mathrm{rpm}$ for $15 \mathrm{~min}$ and sterilized by filtration using $0.2 \mu \mathrm{m}$ membrane filter (Millipore $(\mathcal{C}$, UK). The filtrate was evaporated and the resulted solid weight was used to prepare the require concentrations (Krell, 1996). Proportions of honey and royal jelly was weighed out and mixed into distilled water to achieve required concentrations. This solution was sterilized by filtration through a $0.2 \mu \mathrm{m}$ filter membrane, and was further diluted with sterile distilled water if required. Twenty gram of pollen was extracted by $150 \mathrm{ml}$ ethanol (70\%) for 72 hours and filtered then evaporation process was undertaken. The resulted solid powder was used to prepare the required concentrations. A freeze dried bee venom was dissolved in distilled water to prepare a stock solution. Working solution was fresh prepared immediately before undertaking the disk diffusion bioassay experiment. A wide range of bee product concentrations was prepared containing $0,10,20,40$ and $80 \%(\mathrm{w} / \mathrm{v})$ for honey, royal jelly, pollen and propolis in 70\% ethanol (as constant matrix) while bee venom was prepared in distilled water with concentrations of $0,40,80,160$ and $640 \mathrm{mg} / \mathrm{l}$.

\subsection{Tested pathogen bacteria}

The following test organisms (bacteria) were used: Escherichia coli, Salmonella typhimurium and Salmonella enterica. The bacteria strains were obtained from the Centre of Microbiological Laboratory (CML), Faculty of Environmental Agricultural Sciences, Arish University.

\subsection{Agar disc diffusion bioassay}

Sterilized petri dishes were prepared using $20 \mathrm{ml}$ of sterile Nutrient Agar. The surface of the plates was inoculated using a $100 \mu \mathrm{L}$ of $0.5 \mathrm{McF}$ arland standardized inoculum suspension of bacteria and allowed to dry. The nutrient agar disc diffusion method (Perumalsamy et al., 2006) was employed to test the antibacterial activity of bee products. A sterile paper discs (5 $\mathrm{mm}$ in diameter) were placed on the top of each plate that have different concentrations of bee products; discs were soaked in solution containing different concentrations of each treatments. Discs were soaked in $20 \mu 1$ of $70 \%$ ethanol served as negative control where commercial Augmentin disc $(30 \mu \mathrm{g})$ was used as positive control. The bacterial plates were incubated at $37^{\circ} \mathrm{C}$ for $48 \mathrm{hrs}$. Inhibition zone area (IZA) that observed around the treated paper disc were measured with vernier caliper. The IZA was measured in triplicates and the mean radius was calculated. The IZA was calculated according to the formula (eq. 1) described by Surendra et al. (2011): 
$I Z A=\pi R^{2}-\pi r^{2}$

Where IZA $=$ inhibition zone, $\pi=3.143, \mathrm{R}=$ radius of the inhibition zone and $\mathrm{r}=$ radius of the paper disc. The paper disc area $\left(\pi r^{2}\right)$ was subtracted from the area of the inhibition zone to calculate the absolute mean area of inhibition produced as an effect of each bee product application. Various clear zones, more than $5 \mathrm{~mm}$ in diameter, that were observed at different concentrations of each treatment for varied concentrations were measured in millimeter and the average of the IZA were recorded. All treatments were undertaken in triplicates.

\subsection{Estimation of minimum inhibitory concentration (MIC)}

Minimum inhibitory concentration (MIC) of bee product samples was determined by the method described by Wasihun and Kasa (2016). Nutrient broth was prepared according to manufacturer instructions and employed for testing the proposed concentrations of bee products. Five sterilized clean test tubes were placed in a stand.Each tube except negative control was inoculated with $20 \mathrm{~mL}$ of bacterial suspension $\left(10^{6} \mathrm{cfu} / \mathrm{mL}\right)$ and then incubated at $37^{\circ} \mathrm{C}$ for $24 \mathrm{~h}$. The whole process was repeated for each bee product sample in triplicate against all tested bacteria. The MIC was observed by visual inspections for the presence and absence of growth (turbidity).

\subsection{Determine the potential effect of honey and propolis for milk preservation}

To evaluate the potential effect of honey and propolis in preserving milk, one concentration from each of them was used. Honey and propolis were added to the milk samples and checked for spoilage. A commercially available pasteurized milk (Juhayna milk) samples were obtained from the market and refrigerated fully sealed at $4^{\circ} \mathrm{C}$ until further use. Studies on the preservative use of honey and propolis were done by monitoring the bacterial growth in $500 \mathrm{ml}$ of milk samples. Both bee products were selected for milk preservation depending on the results obtained from pathogenic bacteria related experiments. The milk was stored with $100 \mu \mathrm{l}$ of $500 \mathrm{mg} / \mathrm{ml}(50 \%)$ solution of honey or propolis added, at $4{ }^{\circ} \mathrm{C}$ for 2-8 days and they were compared with a milk sample stored without treatments as negative control. The lower amount of honey and propolis $(100 \mu \mathrm{l})$ were used to avoid any disturbance of the milk sensory properties (Krushna et al., 2007). The bacterial growth was quantitated by measuring the absorbance of $50 \mathrm{ml}$ nutrient broth $(550 \mathrm{~nm})$ inoculated with $100 \mu \mathrm{l}$ milk sample supplemented with honey, propolis and a similar volume of the same milk sample without treatments at $48 \mathrm{hrs}$ intervals for 8 days. In the present experiment the absorbance was taken after incubating the cultures for $10 \mathrm{hr}$ in order to make sure that the cultures do not grow beyond the exponential phase.

\subsubsection{Modelling the growth rate of spoilage bacteria in the milk}

First order exponential growth equation (2) developed from Baranyi and Roberts (1994) was used to model and predict the growth rate of growing up bacteria in tested milk.

$$
Y_{t}=\left(Y_{\text {final }}\left(1-\exp ^{-k t}\right)\right.
$$

where $Y_{t}$ is the growth amount measured as optical denisty (OD) at $550 \mathrm{~nm}$ at the time $t(h), Y_{\text {final }}$ is the final turbidity recorded during the incubation experement (typically after 8 days as OD), and $\mathrm{k}$ is the growing rate coefficient $\left(\mathrm{h}^{-1}\right)$. This equation was primarily used to describe organism growth or mortility as a function of time. The model was optimized using Minitab statistical software (Minitab ${ }^{\circledR}$ 17.1.0). The overall goodness fit for all measured and modelled values was determined based on determination coefficient $\left(\mathrm{R}^{2}\right)$, Pearson coefficient ( $\mathrm{r}$ ) and the residual standard deviation (RSD, eq. 3):

$\mathrm{RSD}=\sqrt{\frac{1}{\mathrm{n}-\mathrm{c}} \sum_{\mathrm{y}=1}^{\mathrm{n}}\left(M_{\mathrm{y}}-\mathrm{P}_{\mathrm{y}}\right)^{2}}$

Where $\mathrm{M}_{\mathrm{y}}$ and $\mathrm{P}_{\mathrm{y}}$ are the measured and predicted values of growth using equation $2, \mathrm{n}$ is the number of the observed values and $\mathrm{c}$ is the number of fitted coefficients in equation 2 (typically $1 ; \mathrm{k}$ ). 


\section{Results and Discussion}

\subsection{Antimicrobial activity of bee products and commercial antibiotic against pathogenic bacteria}

The results of antibacterial activity of different bee products against Escherichia coli (E. coli), Salmonella typhimurium (S. typhi) and Salmonella enterica (S. enterica) are presented in Figure 1. In the present work three gram-negative bacteria were used to investigate the antimicrobial properties of different bee products by using Disc Diffusion Assay (DDA). The sensitivity of three microbial strains was tested against bee venom (BV), honey $(\mathrm{BH})$, royal jelly (RJ), pollen (Po) and propolis (Pr) at different concentrations. The results reveal that all bee products exhibited antimicrobial spectrum to some extend among the selected pathogenic bacteria and added concentrations. Figure 1 shows the antimicrobial effects against $E$. coli. The inhibition zone area ranged from 14.9 to 32.6, 15.8 to 44.5 , 8.20 to $28.2,7.75$ to 16.9 and 28.2 to $65.1 \mathrm{~mm}^{2}$ for BV, BH, RJ, Po and Pr, respectively. The ranged data showed an average with standard deviation values for the whole dataset as $20.9 \pm 11.3,27.6 \pm 15.4$, $16.6 \pm 9.18,13.1 \pm 4.41$ and $37.3 \pm 20.7 \mathrm{~mm}^{2}$ for $\mathrm{BV}, \mathrm{BH}, \mathrm{RJ}$, Po and $\mathrm{Pr}$, respectively. The highest inhibition zone area followed the order of $\mathrm{Pr}>\mathrm{BH}>\mathrm{BV}>\mathrm{RJ}>\mathrm{Po}$, corresponding to the concentrations of the highest one of each treatments with exception of the $20 \%$ of propolis. These findings showed a positive significant relationship $(\mathrm{p}>0.01)$ between concentrations of each bee product and the inhibition zone area (IZA) $(\mathrm{r}>0.7$, taking into account removing the outlier point of IZA at a concentration of $20 \%$ for propolis application; IZA $=65.1 \pm 34.0 \mathrm{~mm}^{2}$ ). The IZA of growing $E$. coli treated by propolis at the concentrations of 40 and $80 \%$ showed values of $41.3 \pm 14.1$ and $43.1 \pm 8.40$ $\mathrm{mm}^{2}$, respectively. Although both values of inhibition zone with propolis were very close to those found with the same concentrations with honey application; $40.7 \pm 11.0$ and $44.5 \pm 17.9 \mathrm{~mm}^{2}$ for 40 and $80 \%$, respectively, they were statistically different $(\mathrm{p}<0.05)$. Our results were in corresponding with the results reported by Ghramh et al. (2019). The authors collected honey samples from different locations of Saudi Arabia and evaluated them against pathogenic bacteria at a concentrations of 80 and $50 \%$. They found that the $80 \%$ of honey application showed superior IZA comparable to $50 \%$ application against $E$. coli. Moreover, the highest antibacterial activity against $E$. coli were observed with Egyptian propolis collected from Dakahlia region (El Hady and Hegazi, 2002). One other observation has been demonstrated from Figure 1 is that the IZA seemed to be constant at a concentration of $40 \%$ for $\mathrm{BH}$, RJ, Po and Pr and $160 \mathrm{mg} / \mathrm{l}$ for BV. This observation suggests that at these concentrations they could be used as antimicrobial agent against $E$. coli instead of their higher concentrations. The Paired $\mathrm{T}$ test showed insignificant difference between treating $E$. coli by $\mathrm{BH}$ and $\operatorname{Pr}(\mathrm{T}$ value $=-1.33, \mathrm{p}=0.26)$.

Regarding the antibacterial properties of all tested bee products against $S$. typhi, Figure 1 shows IZA at different concentrations of BV, BH, RJ, Po and Pr. The results showed antimicrobial effects against $S$. typhi. The IZA ranged from 3.46 to $10.9,7.75$ to $25.8,4.82$ to $19.6,3.46$ to 10.7 and 17.6 to $30.8 \mathrm{~mm}^{2}$ for BV, BH, RJ, Po and Pr, respectively. The ranged data showed an average with standard deviation values for the whole dataset as $7.62 \pm 2.81,17.0 \pm 9.59,9.77 \pm 6.00,7.01 \pm 2.69$ and $22.7 \pm 11.0$ $\mathrm{mm}^{2}$ for BV, BH, RJ, Po and Pr, respectively. The highest IZA followed the order of $\mathrm{Pr}>\mathrm{BH}>\mathrm{RJ}>$ $\mathrm{Po}>\mathrm{BV}$, corresponding to the concentrations of the highest concentration of each treatment with exception of the $40 \%$ of propolis and honey. These findings showed a positive significant relationship $(p<0.01)$ between concentration of each bee product used in the current investigation and the inhibition (IZA) zone area $(r>0.52$, with highest $r$ value in case of $R J ; r=0.99)$. Figure 7 also shows that the concentration of $40 \%$ of both propolis and honey provided the highest IZA $\left(30.8\right.$ and $25.7 \mathrm{~mm}^{2}$, respectively). The results also showed insignificant difference between BV and Po ( $p>0.05)$. Again, the superior results were obtained by applying both HB and Pr to inhibit the growth of $S$. typhi. The results obtained by Tichy and Novak (2000) for using propolis as antibacterial agents were in agreement with the current findings. However, in contrary to E. coli, the Paired T test showed significant difference between treating $S$. typhiwith $\mathrm{HB}$ and $\operatorname{Pr}(\mathrm{T}$ value $=-3.26, \mathrm{p}=0.03)$.

The results relating to $S$. enterica that treated by different concentrations of bee products showed that the IZA ranged from 3.46 to $3.46,14.5$ to $25.8,10.9$ to $14.04,4.82$ to 7.75 and 7.75 to $14.9 \mathrm{~mm}^{2}$ for BV, HB, RJ, Po and Pr, respectively (Figure 1). The ranged data showed an average with standard deviation values for the whole dataset as $3.82 \pm 0.82,16.7 \pm 7.81,11.0 \pm 3.40,5.77 \pm 1.24$ and $9.71 \pm 3.61$ $\mathrm{mm}^{2}$ for BV, HB, RJ, Po and Pr, respectively. The highest inhibition zone area followed the order of $\mathrm{HB}>\mathrm{RJ}>\mathrm{Pr}>\mathrm{Po}>\mathrm{BV}$, corresponding to the concentrations of the highest one of each treatment. 
These findings showed a positive significant relationship $(\mathrm{p}<0.01)$ between concentrations of each bee product used in the current investigation and the IZA $(\mathrm{r}>0.8)$. The highest IZAs of growing $S$. enterica were observed at a concentrations of $80 \%$ treated by propolis and honey; $14.9 \pm 7.30$ and $25.8 \pm 2.69 \mathrm{~mm}^{2}$, respectively. The Paired T test showed significant difference between treating $S$. entericawith HB and $\operatorname{Pr}(\mathrm{T}$ value $=3.35, \mathrm{p}=0.02)$. However, the data depicted in Figure 1 shows insignificant difference between RJ and Pr against $S$. enterica active growth.

In agreement with the current study, bee products such as honey, pollen, propolis, beeswax, royal jelly, and venom, have been gaining reputation of an effective healing agent. It is beyond doubt one of the oldest panacea used by humans. The use of honey as an internal and external health agent is much older than the history of medicine itself (Kuropatnicki et al., 2018). Much of the recent interest in honey stems from its perceived health benefits, especially as a medicine, and there is also growing interest in its medicinal properties. Previous studies have revealed differences in antibacterial and antifungal activity of propolis extracts attributable to a difference in chemical composition and concentration of propolis compounds depending on the bee type involved in collection (Osho and Bello, 2010, Silici and Kutluca, 2005, Seidel et al., 2008).

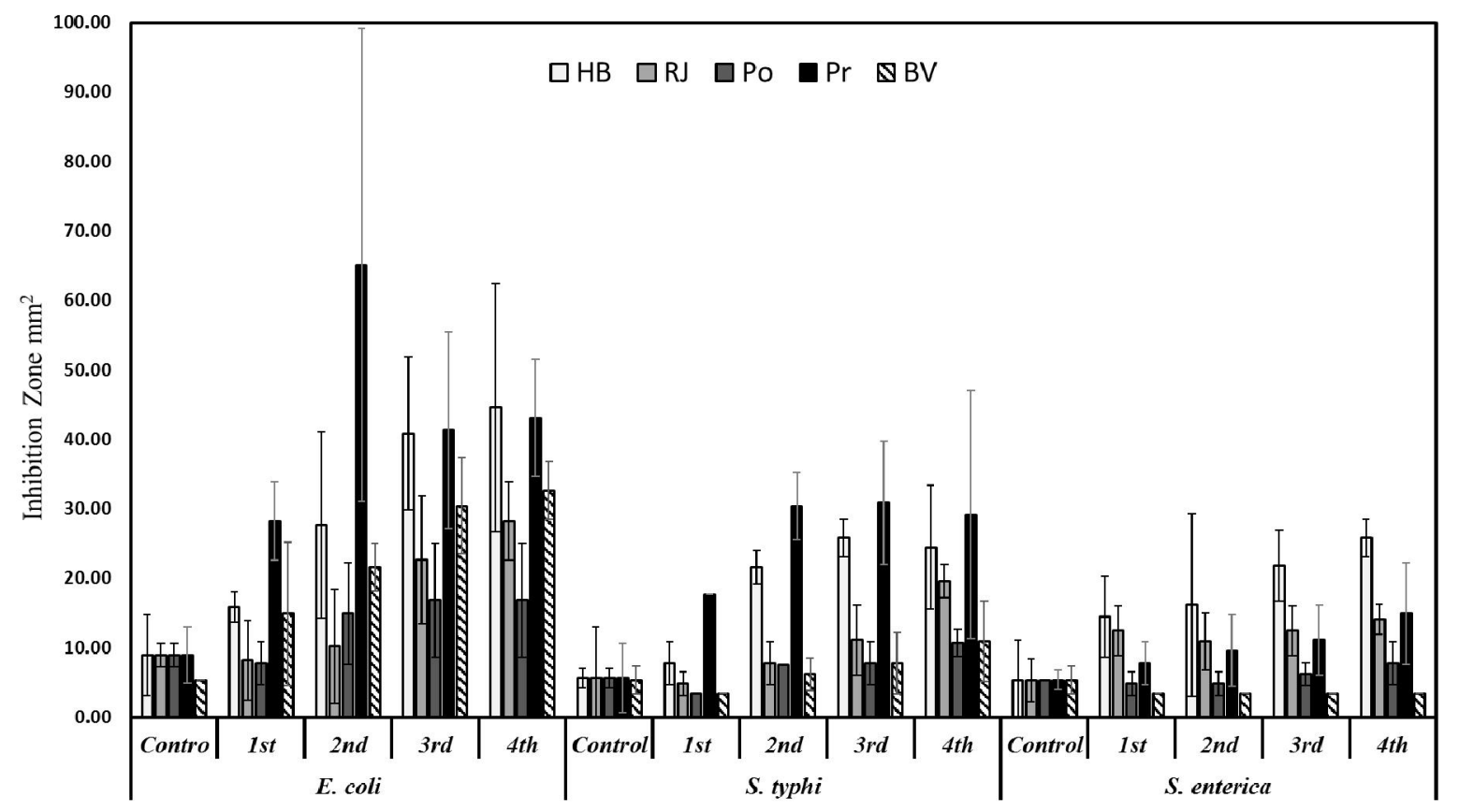

Fig. 1: Inhibition zone area $\left(\mathrm{mm}^{2}\right)$ as a function of different concentrations of bee products against $E$. coli, S. typhi and S. enterica. Y-axis marks of control, $1^{\text {st }}, 2^{\text {nd }}, 3^{\text {rd }}$ and $4^{\text {th }}$ represent in the same sequence the concentrations of $0,10,20,40$ and $80 \%$ for $\mathrm{BH}, \mathrm{RJ}, \mathrm{Po}$, Pr and $0,40,80,160$ and $640 \mathrm{mg} / \mathrm{l}$ for BV. Error bars represent standard deviation of triplicates.

For the reason behind the antimicrobial activities of the most promising results of the current study; honey and propolis was revealed to several factors as reported from literature. For example, The antibacterial potency of honey has been reviewed by Alnaimat (2011) who reported the following reasons; (i) an osmotic effect: honey has a strong osmotic effect since more than $80 \%$ of its composition is a mixture of different monosaccharides, thereby making water available at a minimum level and preventing the growth of many microorganisms ; (ii) a naturally low $\mathrm{pH}$ which inhibits many pathogens; (iii) production of hydrogen peroxide that plays a key role in the antimicrobial activity of honey; (iv) phytochemical factors that have been recognized in honey (e.g. benzyl alcohol, pinocembrin, terpenes, 3, methyl 3,5-dimethoxy-4-hydroxybenzoate and 5-dimethoxy 4-hydroxybenzoic acid), flavonoids and the phenolic acids.

Also, propolis can be characterized broadly into (i) samples from temperate regions (i.e. Europe, North America, New Zealand, western Asia), mainly originating from poplar tree exudates and rich in phenolic compounds such as flavonoids aromatic acids and esters and (ii) samples from tropical areas, 
devoid or containing traces of poplar constituents but rich in other metabolites (Burdock, 1998, Bankova, 2005, Isla et al., 2005, Orsi et al., 2005). However, the precise mode of the antimicrobial action of propolis is still unclear. Studies suggest that it could be linked to multiple targets, with various substances acting in synergy (Amoros et al., 1994, Bonvehí and Coll, 1994, Christov et al., 1999, Arismendi et al., 2018). Furthermore, in vitro experiments have revealed that propolis could synergize the effect of selected antibiotics (Seidel et al., 2008).

Excessive use of antibiotics throughout the world especially in under developed and developing countries may spread resistance in the community and make the eradication of infectious diseases very difficult (Patel and Chauhan, 2017). Comparing the results obtained from disc diffusion bioassay against the three studied pathogenic bacteria with artificial antibiotic used in the current study, Table 1 shows the IZA of Augmentin (AUG) antibiotic contains amoxicillin/clavulanic acid against studied bacteria. The manufacture recommended that this kind of antibiotic is more effective in inhibiting $E$. coli strains' growth (around $22 \mathrm{~mm}$ diameter IZA). This recommendation was in agreement with our findings. The highest IZA was found against $E$. coli $\left(52.8 \pm 7.91 \mathrm{~mm}^{2}\right)$ while both Salmonella sp showed lower IZA. Actually, the IZA values for $S$. typhi and $S$. enterica were very close; $19.6 \pm 4.71$ and $19.8 \pm 2.48 \mathrm{~mm}^{2}$, respectively. Although negative control results (disc without treatment; only $70 \%$ ethanol) showed the lowest IZA for individual result, it showed in some cases higher values than treated samples. This actually because of general average values taken from the whole dataset. Therefore, this average value for the negative control could misleading the reader that $70 \%$ ethanol might be more effective than, for example, bee venom in case of S. enterica in terms of IZA, which is incorrect. So, positive control is useful to compare its results with bee products for several reasons: (i) it could demonstrate the resistance of pathogenic bacteria exist against artificial antibiotic and (ii) help us to find alternative natural antimicrobial agent that could be used for remedying diseases caused by pathogenic bacteria.

Table 1: The zones of inhibition diameter $\left(\mathrm{mm}^{2}\right)$ of Augmentin standard antibiotic $(30 \mu \mathrm{g} / \mathrm{ml})$ on $E$. coli, S. typhi and S. enterica.

\begin{tabular}{lcl}
\hline Pathogenic bacteria & Antibiotic (Augmentin) ${\text { Inhibition zone area } \mathbf{~ m m}^{\mathbf{2}}}$ & SD \\
\hline Escherichia coli & 52.8 & 7.91 \\
Salmonella typhimurium & 19.6 & 4.71 \\
Salmonella enterica & 19.8 & 2.48 \\
\hline
\end{tabular}

The results also implied that AGU produce higher IZA with E. coli bringing higher IZA even more than honey. However, AGU showed lower IZA with $S$. typhi and even lower than honey. Many countries have been reporting multidrug-resistant Salmonella (Kuang et al., 2018). In agreement with the current results, DiMarzio et al. (2013) and Kuang et al. (2018) reported that S. enterica and S. typhi were resistant to commonly used antibiotics. In the other hand, propolis and honey treatments showed higher IZA than AUG which confirm the superior effect of using them as alternative natural antimicrobial agents, in particular with Salmonella sp (Luo et al., 2018). This actually an interesting finding derived by the current study where our results suggesting that emerging resistance for artificial antibiotic against some pathogenic bacteria could be solved by using not only natural products but also nutritional ones such as honey and propolis. Osho and Bello (2010) compared the antibacterial effect in vitro of amoxicillin, tertracyclin and chloramphenicol antibiotics versus the antibacterial effect of two honey solutions at different concentrations $(5,25,50 \& 100 \%)$ against $S$. aureus, P. aeruginosa, E.coli, $K$. pneumonia and $B$. subtilis by the agar diffusion method. They reported that both honeys tested were effective at 25 and $100 \%$ against all the micro-organisms evaluated.

The general trend of the results showed that IZA associated with bacteria strain followed the order of $E$. coli $>S$. typhi $>S$. enterica for all bee product treatments (Figure 1). This comparable finding suggests that antibacterial effects is 'pathogen' and 'bee product' dependent. In another word, the $S$. enterica exhibits the highest resistant against antimicrobial effects of bee products although it provide IZA higher than AUG application as mentioned above. The current study agrees with studies carried out by Taormina et al. (2001), in which they tested antibacterial activity of honey collected from six floral source places against Escherichia Coli, Salmonella thyphimurium, Shigella sonnei, Staphylococcus aureus and Bacillus cereus using disc diffusion method. The authors showed that the 
development of inhibition zone areas depends mainly on the concentration of the bee products used as well as the tested pathogen.

\subsection{Minimum inhibitory concentration (MIC)}

In order to obtain more quantitative and precise results the agar disc diffusion method was compared with the MIC. In the present study the minimum inhibitory concentration (MIC) of the studied bee products including BV, BH, RJ, Po and Po was determined for three pathogenic bacteria (E. coli, $S$. typhi and S. enterica) in nutrient broth culture (Table 2). The minimum inhibitory concentrations (MICs) values of BV against E. coli, S. typhi and S. enterica strains were 80,160 and $80 \mathrm{mg} / \mathrm{l}$, respectively. The microbial population reduction at these concentration reflecting a lethal effect of bee venom. The MICs values of BH against E. coli, S. typhi and S. enterica strains were 20, 40 and $20 \%$, respectively. The MICs values of RJ against E. coli, S. typhi and S. enterica strains were 80, 40 and 40 $\%$, respectively. The MICs values of Po against E. coli, S. typhi and S. enterica strains were 80,80 and $80 \%$, respectively. The MICs values of Pr against E. coli, S. typhi and S. enterica strains were 40, 20 and $20 \%$, respectively. Although It is not always straight forward to compare results obtained from different investigations on the antimicrobial effect of bee products due to the variety of methods used (i.e. bioautography, agar dilution, agar diffusion, broth dilution), (Seidel et al., 2008) the results of BH and Pr provided, at least, promising results as obtained by disc diffusion method.

Table 2: Minimum inhibitory concentration of different bee products samples $n$ against bacterial pathogens

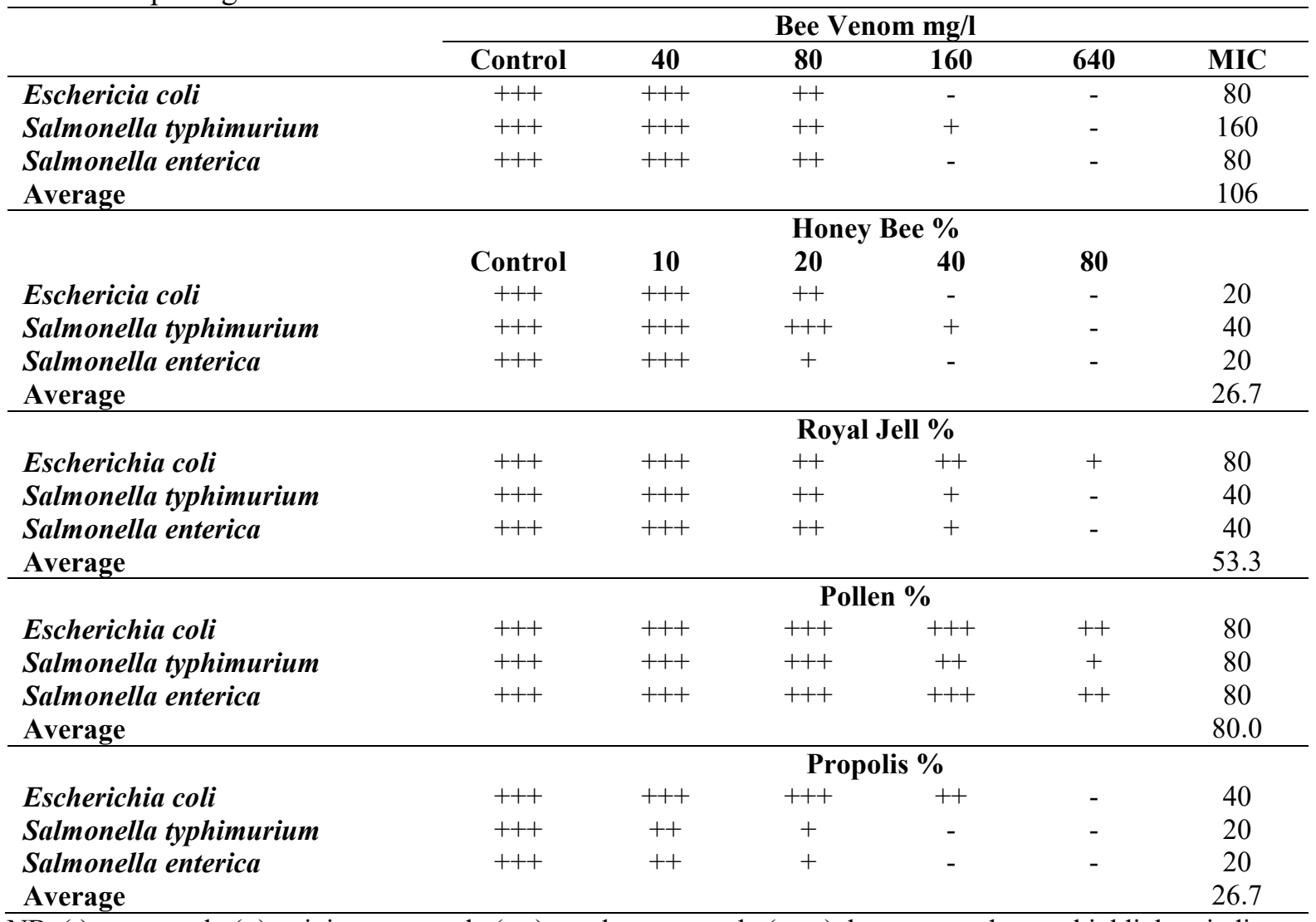

NB: (-), no growth; (+), minimum growth, $(++)$, moderate growth; $(+++)$, heavy growth, grey highlighter indicates the MIC.

In addition, MIC values obtained from the current study using the pollen as antimicrobial activity against tested bacteria were in corresponding with disc diffusion bioassay. It has lower effect than other bee products although to some extend it has IZA higher than that of negative control at higher concentrations $(80 \%)$, corresponding with MIC values $(80 \%)$. It has been acknowledged that some studies have reported the important of bee pollen such as the antimicrobial activity (Basim et al., 2006, Carpes et al., 2007). The order of MIC values as general average regardless tested bacteria (Table 2) 
were $\mathrm{BV}>\mathrm{Po}>\mathrm{RJ}>\mathrm{HB}=\mathrm{Pr}$. This finding suggests that $\mathrm{HB}$ and Pr have a superior effect in inhibiting pathogenic bacteria followed by RJ then Po and BV. Therefore, the lowest MIC has been found corresponding with $20 \%$ concentrations of propolis and honey against $S$. typhi and enterica and E. coli and $S$. enterica, respectively.

\subsection{The potency of bee products to preserve milk: an application approach}

The preservation of milk in the developing countries presents a problem in that, the ambient temperatures tend to be high with limited refrigeration facilities. Moreover, very low levels of microbial contamination in milk samples could actually result in the spoilage of milk samples during shelf life. This poses an additional problem especially in conditions, where the cold chain is a limiting factor (Krushna et al., 2007). From this point of view, the robust of both honey and propolis inhibitory activities against pathogenic bacteria has been investigated to preserve milk from spoilage. Both bee products have been selected among tested ones. This was clearly depending on the obtained results from disc diffusion and MIC assays. It is well known that honey has been extensively used as food preservation including milk (Krushna et al., 2007) but to our best knowledge, propolis has not been used before for milk preservation except the recent study undertaken by Thamnopoulos et al. (2018). This section serve as an effective application of using the antimicrobial spread spectrum properties of honey and propolis in preserving milk from spoilage during its storage home time.

\subsection{Bacterial growth in milk treated by honey and propolis}

In an attempt to evaluate the possible use of honey and propolis as a natural preservative for milk, milk samples stored at $4^{\circ} \mathrm{C}$ from 2 to 8 days in the presence or absence of honey or propolis were assayed for their bacterial content and growth. The addition of both honey and propolis at a final concentration of $50 \mathrm{mg} / \mathrm{ml}$ had a considerable inhibitory effect on the growth of bacteria in comparison to milk samples devoid of treatments (Figures 2 and 3). The in vitro antibacterial (bacteriostatic or bactericidal) properties of propolis extracts against spoilage and pathogenic foodborne Gram-positive and Gram-negative bacteria have been documented by several researchers via agar-diffusion assays or experiments in liquid broths (Boyanova et al., 2006, Da Silva et al., 2006, Kalogeropoulos et al., 2009, Kim and Chung, 2011).Turbidity of milk measured at $550 \mathrm{~nm}$ was plotted against milk storage days in Figure 2. The data were well fitted to polynomial fitting line with R2 values of $0.977,0.959$ and 0.955 for milk without treatment (control), milk with honey and milk with propolis, respectively. The results showed that bacteria growth was lower in milk treated with propolis as a function of storage day and provided good results comparing with control. The turbidity ranged from $0.63 \pm 0.08$ to $1.97 \pm 0.09$, $0.50 \pm 0.6$ to $0.94 \pm 0.01$ and $0.45 \pm 0.04$ to $0.78 \pm 0.05$ for milk without treatment, milk with honey and milk with propolis, respectively. These results suggests an increase in inhibition of bacteria growth in the stored milk as a function of time (Figure 3). It should be reported that although the pathogen is effectively controlled upon proper pasteurization, in rare instances of post-pasteurization contamination from sources in the plant environment, the presence of L. monocytogenes in the finished product is possible (Frye and Donnelly, 2005) and pasteurized milk has been implicated in L. monocytogenes foodborne outbreaks in the past (Dalton et al., 1997). On the other hand both honey and propolis showed antimicrobial activity of against several bacterial species known to cause spoilage of food and the anti bacterial activity of both products on several food borne pathogens has been proved but they are vried from study to another according to the collecting locations the expermintal conditions (Krushna et al., 2007, Thamnopoulos et al., 2018).

Inhibitory effect on the growth of bacteria in treated milk with propolis was higher than that of milk treated by honey where the values ranged from $35.9 \pm 11.5$ to $52.4 \pm 1.97$ and $27.4 \pm 3.10$ to $60.4 \pm 1.43 \%$ for honey and propolis, respectively (Figure 3). In a study undertaken by Krushna et al. (2007), the authors stored milk samples for different time periods (3, 4, $5 \& 6$ days) in the presence of honey, showed around $50-55 \%$ decrease in turbidity compared to the samples that were preserved without honey which is somehow were relevant to the current study. Moreover, flavonoids component in propolis have been reported to exhibit significant antibacterial activity, with galangin, pinocembrin and pinobanksin being recognized as the most effective flavonoid agents against bacteria (Dimov et al., 1992). In attempt to show the statistically relationship between milk treated by honey and propolis, paired $\mathrm{T}$ - test showed a highly significant difference between the two treatments $(\mathrm{T}$ value $=-12.5 ; \mathrm{p}=$ $0.001)$. 


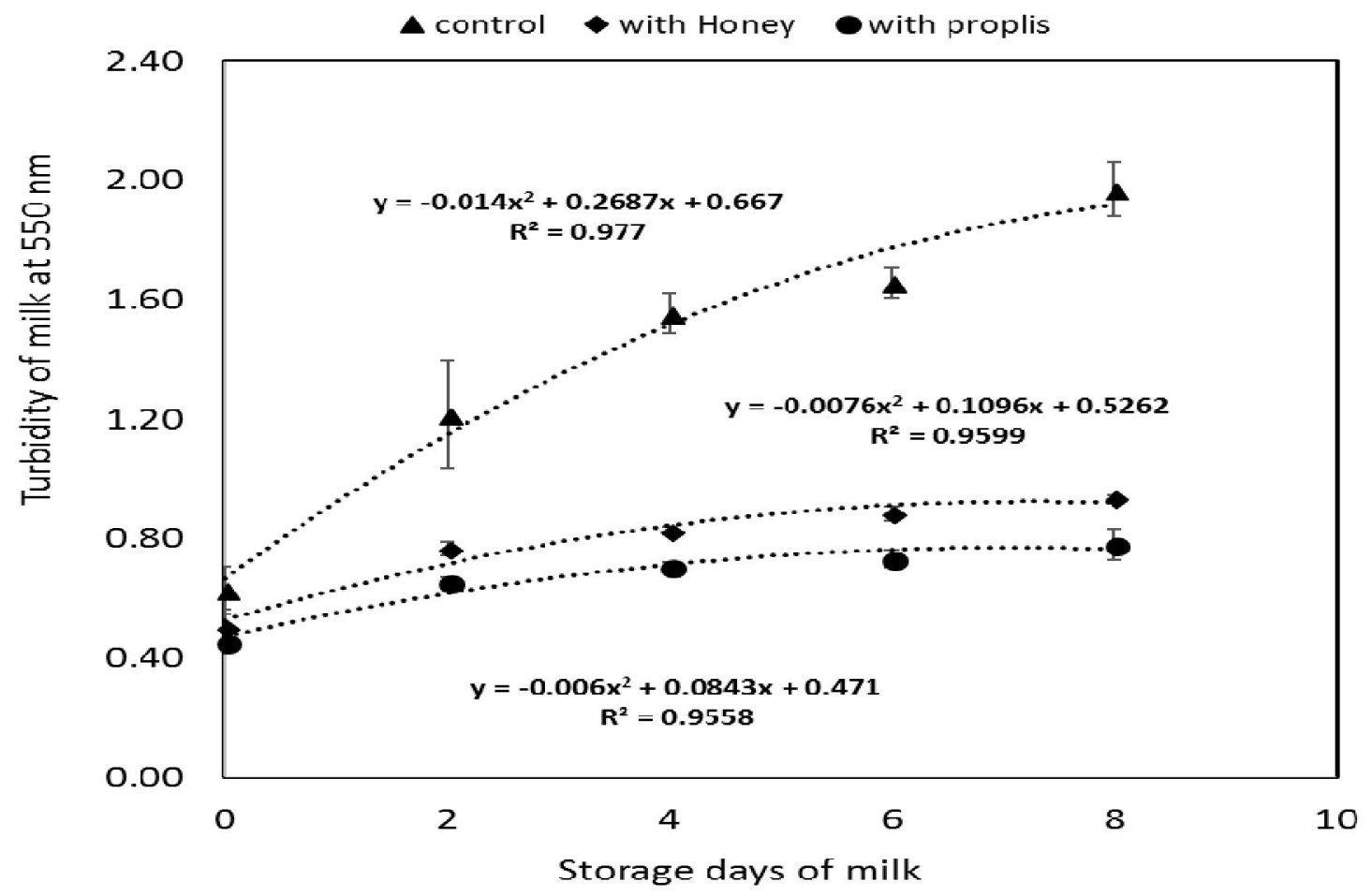

Fig. 2: Turbidity measurements as optical density at $550 \mathrm{~nm}$ of bacterial growth treated with or without honey and propolis as a function of storage time. The broken lines represent polynomial fitting and error bars represent standard deviation of triplicates.

IGH $\mathbf{Q I G P}$

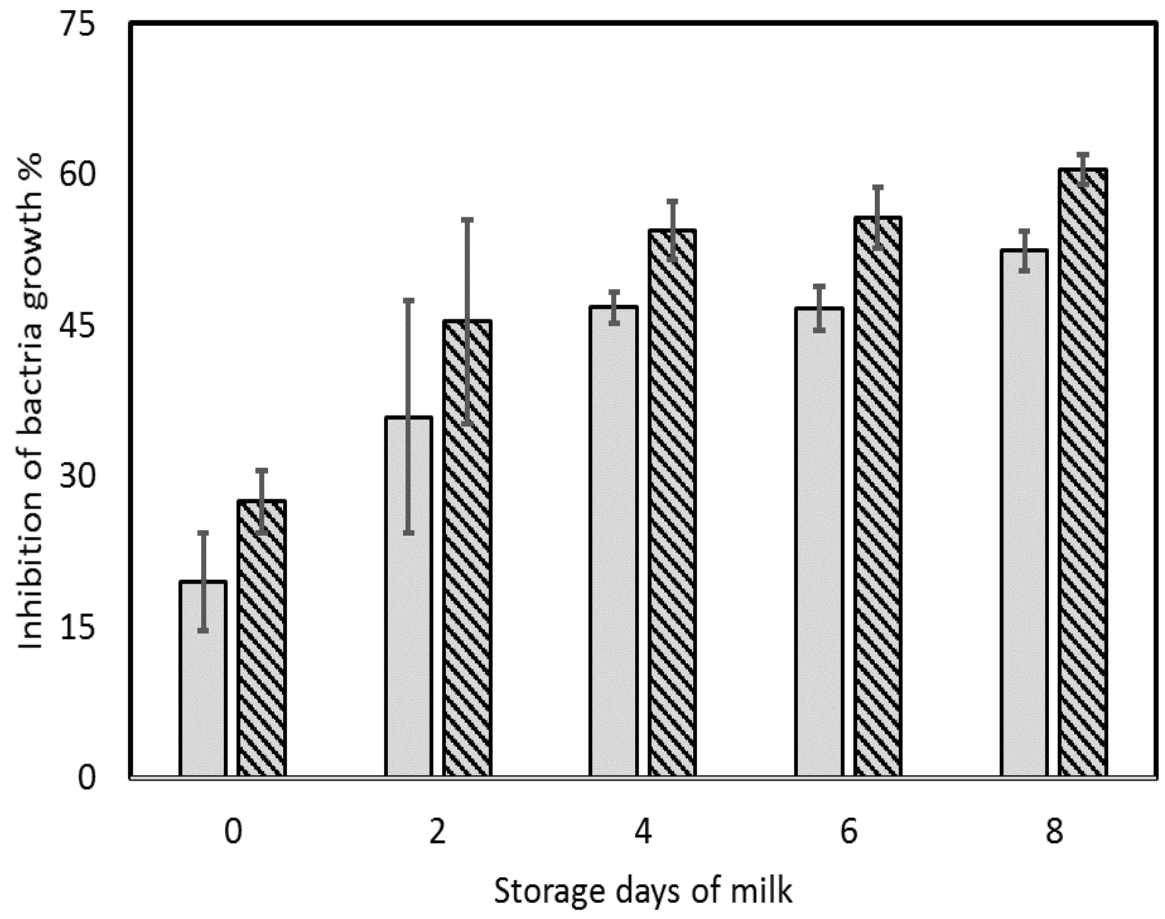

Fig. 3: Inhibition of bacteria growth (\%) in milk treated by honey (IGH) and propolis (IGP) as a function of storage time. Error bars represent standard deviation of triplicates. 


\subsection{Predicting bacteria growth in milk as a function of time}

A growth equation model has been used in predicting bacteria growth in milk as a function of time. The objective of this prediction model is to set the steady state time that bacteria could not be able to grow more as a result of honey or propolis. Figure 4 represents the model results obtained from applying equation 2 . Approximately $95 \%, 85 \%$ and $87 \%$ of the variability in the bacterial growth in milk, milk with honey and milk with propolis, respectively, were explained by growth equation model (Figure 4); RSD values were a little over $0.2 \%$.

The best model performance was recorded with milk treated with propolis as judged from RSD value; RSD values for milk without treatment, milk with honey and milk with propolis were $0.23,0.08$ and 0.06 , respectively. However, R2 values were much better with control compared to other treatments; R2 values for milk without treatment, milk with honey and milk with propolis were 0.955 , 0.859 and 0.870 , respectively. In a pragmatic point of view, the model demonstrates that the milk without any treatment (control) showed a good growing curve (Figure 4) by which the highest growth rate was established at 41.5 days. However, the same values in case of bacterial growth in milk treated by honey and propolis were 1.20 and 0.80 days, respectively. These modelled values implied that bacteria growth in milk without treatments had not any obstacles or limitations to growth except the cool conditions. However, the milk treated with both bee products inhibit the bacteria growth to be minimal with the superiority of using propolis compare with honey as a milk preservation from spoilage. Actually, this model confirm the advantage of using propolis and honey (with a favour of propolis over honey) for preserving milk for longer life as well as adding nutritional component to the drinking milk and avoiding chemical preservative compound that may led to several disease to the people.

Propolis ethanolic extract can be efficiently added into milk. The addition of propolis in milk, artificially contaminated with $L$. monocytogenes, resulted in a pronounced and dose-dependent antilisterial effect during storage at $4{ }^{\circ} \mathrm{C}$. Milk with added propolis received average consumer acceptability scores, indicating that there may be room, e.g. upon inclusion of additional (combinations of) flavor compounds, for the development of a propolis-flavored dairy drink with desirable organoleptic properties (Thamnopoulos et al., 2018).

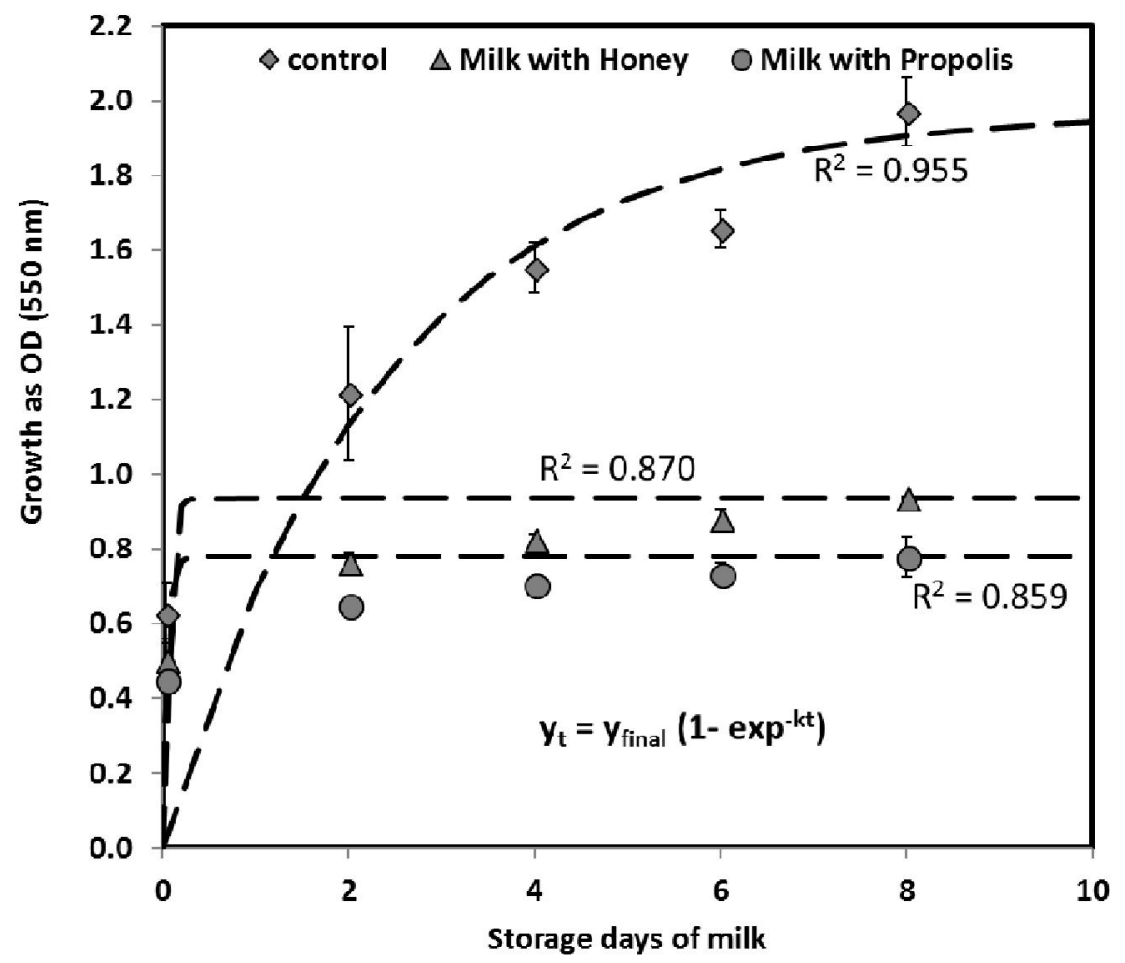

Fig. 4: Predicting growth of bacteria measured as optical density at $550 \mathrm{~nm}$ according to equation 2 for milk treated with propolis or honey as a function of storage days. Dash line represent the model fitting trend and error bars represent standard deviation of triplicates. 


\section{References}

Alnaimat, S., 2011. A contribution to the study of biocontrol agents apitherapy and other potential alternatives to antibiotics. University of Sheffield.

Amoros, M., E. Lurton, J. Boustie, L. Girre, F. Sauvager, and M. Cormier, 1994. Comparison of the anti-herpes simplex virus activities of propolis and 3-methyl-but-2-enyl caffeate. Journal of Natural Products, 57: 644-647.

Arismendi, N., M. Vargas, M.D. López, Y. Barría, and N. Zapata, 2018. Promising antimicrobial activity against the honey bee parasite Nosema ceranae by methanolic extracts from Chilean native plants and propolis. Journal of Apicultural Research, 1-14.

Bankova, V., 2005. Recent trends and important developments in propolis research. Evidence-Based Complementary and Alternative Medicine, 2: 29-32.

Baranyi, J. and T.A. Roberts, 1994. A dynamic approach to predicting bacterial growth in food. International Journal of Food Microbiology, 23: 277-294.

BASIM, E., H. Basim, and M. Özcan, 2006. Antibacterial activities of Turkish pollen and propolis extracts against plant bacterial pathogens. Journal of Food Engineering, 77, 992-996.

Bonvehí, J.S. and F.V. Coll, 1994. The composition, active components and bacteriostatic activity of propolis in dietetics. Journal of the American Oil Chemists' Society, 71: 529-532.

Boyanova, L., R. Kolarov, G. Gergova, and I. Mitov, 2006. In vitro activity of Bulgarian propolis against 94 clinical isolates of anaerobic bacteria. Anaerobe, 12: 173-177.

Burdock, G. 1998. Review of the biological properties and toxicity of bee propolis (propolis). Food and Chemical toxicology, 36: 347-363.

Carpes, S.T., R. Begnini, S.M.D. Alencar, and M.L. Masson, 2007. Study of preparations of bee pollen extracts, antioxidant and antibacterial activity. Ciência e Agrotecnologia, 31: 1818-1825.

Christov, R., V. Bankova, I. Tsvetkova, A. Kujumgiev, and A.D. Tejera, 1999. Antibacterial furofuran lignans from Canary Islands propolis. Fitoterapia, 70: 89-92.

Da Silva, J.F.M., M.C. De Souza, S.R. Matta, M.R. De Andrade, and F.V.N. Vidal, 2006. Correlation analysis between phenolic levels of Brazilian propolis extracts and their antimicrobial and antioxidant activities. Food Chemistry, 99: 431-435.

Dalton, C.B., C.C. Austin, J. Sobel, P.S. Hayes, W.F. Bibb, L.M. Graves, B. Swaminathan, M.E. Proctor, and P.M. Griffin, 1997. An outbreak of gastroenteritis and fever due to Listeria monocytogenes in milk. New England Journal of Medicine, 336: 100-106.

Dimarzio, M., N. Shariat, S. Kariyawasam, R. Barrangou, and E.G. Dudley, 2013. Antibiotic resistance in Salmonella enterica serovar Typhimurium associates with CRISPR sequence type. Antimicrobial Agents and Chemotherapy, 57: 4282-4289.

Dimov, V., N. Ivanovska, V. Bankova, and S. Popov, 1992. Immunomodulatory action of propolis: IV. Prophylactic activity against gram-negative infections and adjuvant effect of the water-soluble derivative. Vaccine, 10: 817-823.

El Hady, F.K.A. and A.G. Hegazi, 2002. Egyptian propolis: 2. Chemical composition, antiviral and antimicrobial activities of East Nile Delta propolis. Zeitschrift für Naturforschung C, 57: 386394.

Frye, C. and C.W. Donnelly, 2005. Comprehensive survey of pasteurized fluid milk produced in the United States reveals a low prevalence of Listeria monocytogenes. Journal of Food Protection, 68: 973-979.

Ghramh, H.A., K.A. Khan, and A.M.A. Alshehri, 2019. Antibacterial potential of some Saudi honeys from Asir region against selected pathogenic bacteria. Saudi Journal of Biological Sciences, 26 (6), 1278-1284.

Isla, M.I., J.F. Paredes-Guzman, M. Nieva-Moreno, H. Koo, and Y.K. Park, 2005. Some chemical composition and biological activity of northern Argentine propolis. Journal of Agricultural and Food Chemistry, 53: 1166-1172.

Kalogeropoulos, N., S.J. Konteles, E. Troullidou, I. Mourtzinos, and V.T. Karathanos, 2009. Chemical composition, antioxidant activity and antimicrobial properties of propolis extracts from Greece and Cyprus. Food Chemistry, 116: 452-461.

Kim, Y.-H. and H.-J. Chung, 2011. The effects of Korean propolis against foodborne pathogens and transmission electron microscopic examination. New Biotechnology, 28: 713-718. 
Krell, R., 1996. Value-added products from beekeeping .FAO Food and Agriculture Organization of The United Nations Roma; 409.

Krushna, N., A. Kowsalya, R. Srinivasan, and B.R. Narayanan, 2007. Honey as a natural preservative of milk. Indian Journal of Experimental Biology, 45: 459-64.

Kuang, D., J. Zhang, X. Xu, W. Shi, S. Chen, X. Yang, X. Su, X. Shi, and J. Meng, 2018. Emerging high-level ciprofloxacin resistance and molecular basis of resistance in Salmonella enterica from humans, food and animals. International Journal of Food Microbiology, 280: 1-9.

Kuropatnicki, A.K., M. Kłósek, and M. Kucharzewski, 2018. Honey as medicine: historical perspectives. Journal of Apicultural Research, 57: 113-118.

Luo, Y., W. Yi, Y. Yao, N. Zhu, and P. Qin, 2018. Characteristic diversity and antimicrobial resistance of Salmonella from gastroenteritis. Journal of Infection and Chemotherapy, 24: 251-255.

Orsi, R.O., J.M. Sforcin, S.R. Funari, and V. Bankova, 2005. Effects of Brazilian and Bulgarian propolis on bactericidal activity of macrophages against Salmonella typhimurium. International Immunopharmacology, 5: 359-368.

Osho, A. and O. Bello, 2010. Antimicrobial effect of honey produced by Apis mellifera on some common human pathogens. Asian J. Exp. Biol. Sci., 1: 875-880.

Patel, A. and P.B. Chauhan, 2017. Antimicrobial effect of Honey on MRSA isolated from pus samples. International Journal of Drug Research and Technology, 6, 5.

Perumalsamy, R., A. Pachiappan, P. Gopalakrishnakone, M. Maung, E.H. Yap, T.C. Vincent, B. Ho, and T.W. Joseph, 2006. In vitro antimicrobial activity of natural toxins and animal venoms tested against Burkholderia pseudomallei. BMC Infect. Dis, 4: 35-40.

Rahman, M.M., M. Alam, N. Fatima, H.M. Shahjalal, S.H. Gan, and M. Khalil, 2017. Chemical composition and biological properties of aromatic compounds in honey: An overview. Journal of Food Biochemistry, 41(6):e12405. https://doi.org/10.1111/jfbc.12405

Ribeiro, C.F.A., G.G.O. Silveira, E.S. Candido, M.H. Cardoso, C.M.E. Carvalho, and O.L. Franco, 2020. Effects of Antibiotic Treatment on Gut Microbiota and How to Overcome Its Negative Impacts on Human Health. ACS Infect. Dis., 6 (10): 2544-2559

Seidel, V., E. Peyfoon, D.G. Watson, and J. Fearnley, 2008. Comparative study of the antibacterial activity of propolis from different geographical and climatic zones. Phytotherapy Research, 22: 1256-1263.

Silici, S. and S. Kutluca, 2005. Chemical composition and antibacterial activity of propolis collected by three different races of honeybees in the same region. Journal of Ethnopharmacology, 99, 6973.

Sipos, P., H. Gyory, K. Hagymási, P. Ondrejka, and A. Blázovics, 2004. Special wound healing methods used in ancient Egypt and the mythological background. World Journal of Surgery, 28: 211.

Surendra, N., G. Jayaram, and M. Reddy, 2011. Antimicrobial activity of crude venom extracts in honeybees (Apis cerana, Apis dorsata, Apis florea) tested against selected pathogens. African Journal of Microbiology Research, 5: 2765-2772.

Taormina, P.J., B.A. Niemira, and L.R. Beuchat, 2001. Inhibitory activity of honey against foodborne pathogens as influenced by the presence of hydrogen peroxide and level of antioxidant power. International Journal of Food Microbiology, 69: 217-225.

Thamnopoulos, I.-A.I., G.F. Michailidis, D.J. Fletouris, A. Badeka, M.G. Kontominas, and A.S. Angelidis, 2018. Inhibitory activity of propolis against Listeria monocytogenes in milk stored under refrigeration. Food Microbiology, 73: 168-176.

Tichy, J. and J. Novak, 2000. Detection of antimicrobials in bee products with activity against viridans streptococci. The Journal of Alternative and Complementary Medicine, 6, 383-389.

Wasihun, A.G. and B.G. Kasa, 2016. Evaluation of antibacterial activity of honey against multidrug resistant bacteria in Ayder Referral and Teaching Hospital, Northern Ethiopia. SpringerPlus, 5: 842. 